\title{
A retrospective analysis of postoperative hypokalemia in pituitary adenomas after transsphenoidal surgery
}

\author{
Lili You ${ }^{1}$, Wenpeng Li ${ }^{2}$, Tang Chen ${ }^{2}$, Dongfang Tang ${ }^{2}$, Jinliang You ${ }^{2}$ ， Feng Xian Zhang ${ }^{\text {Corresp. } 2}$ \\ ${ }^{1}$ First Hospital of Jilin University, Division of Clinical Epidemiology, Changchun, China \\ 2 First Hospital of Jilin University, Department of Neurosurgery, Changchun, China \\ Corresponding Author: Feng Xian Zhang \\ Email address: 18343113238@163.com
}

Background. Pituitary adenoma is one of the most common intracranial neoplasms, and its primary treatment is endoscopic endonasal transsphenoidal tumorectomy. Postoperative hypokalemia in these patients is a common complication, and is associated with morbidity and mortality. This study aimed to analyze the etiopathology of postoperative hypokalemia in pituitary adenomas after endoscopic transsphenoidal surgery.

Methods and Materials. This retrospective study included 181 pituitary adenomas confirmed by histopathology. Unconditional logistic regression analysis was used to calculate odds ratios (ORs) and 95\% confidence intervals (Cls). Repeated measures ANOVA was used to analyze change in serum potassium levels at different time points.

Results. Multiple Logistic regression analysis revealed that only ACTH-pituitary adenoma (OR=4.92, $95 \% \mathrm{Cl}: 1.18-20.48, P=0.029)$ had a significant association with postoperative hypokalemia. Moreover, the overall mean serum potassium concentration was significantly lower in the ACTH versus the nonACTH group (3.34 mmol/L vs. $3.79 \mathrm{mmol} / \mathrm{L}, P=0.001$ ). Postoperative hypokalemia was predominantly found in patients with ACTH-pituitary adenoma $(P=0.033)$.

Conclusions. ACTH-pituitary adenomas may be an independent factor related postoperative hypokalemia in patients despite conventional potassium supplementation in the immediate postoperative period. 


\section{RESEARCH ARTICLE}

2 A retrospective analysis of postoperative hypokalemia in pituitary adenomas after transsphenoidal

3 surgery

4 Lili You ${ }^{1 *}$, Wenpeng Li²*, Tang Chen², Dongfang Tang ${ }^{2}$, Jinliang You ${ }^{2}$, Xianfeng Zhang ${ }^{2}$

$5 \quad{ }^{1}$ Division of Clinical Epidemiology, First Hospital of Jilin University, Changchun, China

$6 \quad{ }^{2}$ Department of Neurosurgery, First Hospital of Jilin University, Changchun, China

$7 \quad *$ These authors contributed equally to this work.

8 Correspondence should be addressed to Xianfeng Zhang: 18343113238@163.com

9 Xianfeng Zhang, MD, PhD, Department of Neurosurgery, First Hospital of Jilin University, Changchun

10 130021, Jilin Province, China 


\section{Abstract}

13 Background. Pituitary adenoma is one of the most common intracranial neoplasms, and its primary treatment is endoscopic endonasal transsphenoidal tumorectomy. Postoperative hypokalemia in these patients is a common complication, and is associated with morbidity and mortality. This study aimed to analyze the etiopathology of postoperative hypokalemia in pituitary adenomas after endoscopic transsphenoidal surgery.

Methods and Materials. This retrospective study included 181 pituitary adenomas confirmed by histopathology. Unconditional logistic regression analysis was used to calculate odds ratios (ORs) and 95\% confidence intervals (CIs). Repeated measures ANOVA was used to analyze change in serum potassium levels at different time points.

Results. Multiple Logistic regression analysis revealed that only ACTH-pituitary adenoma (OR=4.92, 95\%CI: $1.18-20.48, P=0.029)$ had a significant association with postoperative hypokalemia. Moreover, the overall mean serum potassium concentration was significantly lower in the ACTH versus the nonACTH group (3.34 mmol/L vs. $3.79 \mathrm{mmol} / \mathrm{L}, P=0.001)$. Postoperative hypokalemia was predominantly found in patients with ACTH-pituitary adenoma $(P=0.033)$.

Conclusions. ACTH-pituitary adenomas may be an independent factor related postoperative hypokalemia in patients despite conventional potassium supplementation in the immediate postoperative period. 


\section{INTRODUCTION}

31 Pituitary adenomas account for approximately 15\% of all intracranial neoplasms(Ezzat et al., 2004; Gold,

1981) and have characteristic clinical manifestations due to overproduction or insufficient secretion of

hypophyseal hormones and/or local mass effects(Mete \& Asa, 2012; Scangas \& Laws, 2014). Pituitary

adenomas are categorized by secretory activity; null cell adenomas and prolactinomas (PRL) are the most

common pituitary adenomas, followed by growth hormone (GH)-pituitary adenomas, adrenocorticotropic

hormone (ACTH)-pituitary adenomas, follicle-stimulating hormone (FSH)-pituitary adenomas, and thyroid-stimulating hormone (TSH)-pituitary adenomas(Ezzat et al., 2004; Lake et al., 2013; Melmed, 2015). Pituitary adenomas are usually monoclonal benign epithelial tumors and rarely turn malignant(Melmed, 2011; Melmed, 2015). Endonasal transsphenoidal surgery has proved a safe and efficacious treatment of pituitary adenomas(Constantino et al., 2016; Wang et al., 2015; Zhan et al., 2015).

Hypokalemia is defined as a value of serum potassium concentration less than $3.5 \mathrm{mmol} / \mathrm{L}$, and is the most common electrolyte abnormality encountered in clinical practice(Glover, 1999; Halperin \& Kamel, 1998). Most patients have mild hypokalemia, but nearly one quarter have serum potassium concentrations below $2.5 \mathrm{mmol} / \mathrm{L}$, defined as severe hypokalemia, which can cause many signs and symptoms such as fatigue, nausea, vomiting, and muscle weakness(Lodin \& Palmer, 2015; Weir \& Espaillat, 2015). Moreover, unrecognized hypokalemia can lead to respiratory failure and is associated with morbidity and mortality (Wojtaszek \& Matuszkiewicz-Rowinska, 2013). in a consecutive series of patients with pituitary adenomas after transsphenoidal surgery. 


\section{MATERIALS AND METHODS}

\section{Study population}

54 We retrospectively reviewed the medical records of 181 consecutive patients of pituitary adenomas from the Department of Neurosurgery, First Hospital of Jilin University (Changchun, China) treated from January 2010 to December 2012. All patients underwent endoscopic endonasal transsphenoidal surgery, and tumor resection was carried out by the same surgeon. Among these, 115 patients had histopathologyproven functioning adenomas and 66 had clinically nonfunctioning adenomas. We then analyzed data obtained from all cases. None of the subjects received chemotherapy or radiotherapy before/after surgery, and patients with previous pituitary surgery and lesions other than pituitary adenomas were excluded from selective adenectomy were excluded. All patients were of Han descent from the Changchun area. Patient characteristics and clinical details were obtained from medical records. We adhered to the bioethics principles of the Declaration of Helsinki, and this study was approved by the Ethics Committee of the First Hospital of Jilin University. (Reference Number: 2016-324).

\section{Preoperative evaluation}

All patients mainly underwent a preoperative neuroradiological and biochemical evaluation. Additionally, baseline information such as sex, age at operation, type of residence, rural/urban geography, length of stay, and history of hypertension or diabetes were included.

All patients underwent diagnostic computed tomographic (CT) scanning, and some had magnetic 
recorded from neuroradiological images, and tumor was classified according to size based on its maximum diameter into 2 categories: microadenoma $(<1.0 \mathrm{~cm})$ and macroadenoma $(\geq 1.0 \mathrm{~cm})$.

Biochemical examination should carefully screen the hypothalamus-pituitary-adrenal (HPA) axis, with a focus on pituitary function, to check for preoperative endocrine excess or insufficiency. Multiple measurements of plasma PRL, GH, ACTH, FSH, and TSH were done. In addition, levels of free thyroxine, insulin-like factor-1 (IGH-1), and 24-h urinary free cortisol as well as glucose on an oral glucose tolerance test (OGTT) were measured when necessary, and the details of the endocrine disgnosis for pituitary adenomas in each types are shown in table 1 . Secretory syndromes must be excluded when pituitary adenomas are preoperatively diagnosed; therefore, a diagnosis of pituitary adenoma must be based on combined results from imaging and endocrinology.

\section{Postoperative evaluation}

All subjects in this study consented to endoscopic endonasal transsphenoidal surgery. Histopathologic examination was conducted immediately at the pathology department of the same hospital for a confirmative diagnosis of adenoma type. Four micrometers thick serial sections of the paraffin-embedded block was excised, and sections from each case were stained with routine Hematoxylin and Eosin method for histopathologic evaluation. Paraffin sections of each tumor were immunostained using the primary antibodies against the following pituitary hormones: PRL, GH, ACTH, FSH, TSH, LH (Zhongshan, Beijing, China). Visualization of the immune reactions was done by Streptavidin-Biotin-peroxidase technique, and 3, 3-diaminobenzidine was employed as a chromogen. The immunostaining results for each patient were graded as being 0 (negative), $1+(10-30 \%$ of cells), $2+(30-50 \%$ of cells) or $3+$ (over $50 \%$ of cells) by the pathologists. The presence of more than $10 \%$ of hormone immunopositive cells was 
93

94

95

96

97

considered secretory tumor. The tumors with high co-expression immunoreactivity were considered Mixpituitary adenomas.

In the early postoperative period, patients were treated in the intensive care unit (ICU) and, at the same time, a CT scan was done to check surgical outcome. Levels of serum ions were measured and a neurological examination and visual field assessment were conducted and recorded for all patients with pituitary adenoma. Follow-up MRI was performed on the first postoperative day and, thereafter, at 3 and 6 months.

Levels of serum potassium were immediately measured postoperatively and repeated a total of 4 times until the third postoperative day for all patients who underwent surgery, and conventional potassium supplementation was done to prevent postoperative hypokalemia. For patients with confirmed hypokalemia, serum potassium was monitored until concentrations returned to normal. Intravenous potassium supplementation was initiated for patients with intractable hypokalemia. In general, serum potassium levels would become normal within 2 to 3 days.

To explore the relationship between ACTH-pituitary adenomas and postoperative hypokalemia, 16 cases of hypokalemia patients were included, of which eight can be classified as ACTH group and the others were non-ACTH group. Cases would be included in the ACTH group if (1) the clinical manifestation of patients were mainly including central obesity, hypertension, facial plethora, proximal muscle weakness, dacreased libido or impotence and so on; and (2) patients underwent CT scanning or MRI examination confirmed the presence of intracranial tumors; and (3) biochemical examination results of 24-hour urine free cortisol, late-night salivary cortisol and 1-mg overnight dexamethasone suppression were positive (levels of results were elevated). If not, the patients would been divided into non-ACTH 
114

115

116

117

118

119

120

121

122

123

124

125

126

127

128

129

130

131

132

133

134

group.

\section{Criteria for hypokalemia}

For patients with pituitary adenomas, parameters of hepatic and renal function, blood electrolytes, lipids and blood glucose were measured at admission, with a predominant focus on serum potassium, especially on the day of surgery. Data on serum potassium were recorded by obtaining a daily list of medical inpatients from the database of the biochemistry laboratory, where serum potassium was measured by direct ion selective method using an autoanalyzer (DXC800-(5416); Beckman Coulter, USA). Normal serum potassium levels range from 3.5 to $5.5 \mathrm{mmol} / \mathrm{L}$, and a level $<3.5 \mathrm{mmol} / \mathrm{L}$ is defined as hypokalemia. The patient's medical records were located and evaluated to identify if they had mild, moderate, or severe hypokalemia, in the range of $3.0-3.5 \mathrm{mmol} / \mathrm{L}, 2.5-3.0 \mathrm{mmol} / \mathrm{L}$, and $<2.5 \mathrm{mmol} / \mathrm{L}$ levels, respectively.

\section{Statistical analysis}

Demographics and baseline characteristics of subjects were presented as mean values \pm standard deviation for continuous data with normal distribution. Categorical data were displayed as percentage and frequency. Continuous and normal distribution data were compared by Student's $t$ test or ANOVA. Categorical data were compared using the chi-square or Fisher's exact test, as appropriate. Repeated measures ANOVA was used to analyze changes in serum potassium levels with time, Mauchly's test of sphericity should be used to judge whether there were relations among the repeatedly measured datas. If any $(P<0.05)$, multivariate ANOVA should be taken next, or Greenhouse-Geisser corrected results should be taken. Treated effect could be evaluated by estimating between the subject variance. Repeated measurement effect or its interactive effect with treated group could be evaluated by estimating within subject variance. Further, unconditional logistic regression analysis was used to calculate odds ratios 
135 (ORs) and 95\% confidence intervals (CIs). For independent predictive factors of hypokalemia, 136 multivariate logistic regression analysis was performed, with a significance level of $P<0.05$ for inclusion 137 and $P>0.10$ for exclusion of variables and the stepwise selection method was used to automatically 138 choose the variables. All statistical assessments were performed using SPSS18.0 software (SPSS Inc., 139 USA). Two-tailed $P$-values $<0.05$ were considered indicative of statistical significance.

\section{RESULTS}

\section{Subject characteristics}

142 In total, 181 pituitary adenomas (patient mean age $46.6 \pm 13.2$ years at operation; 76 male [42.0\%; mean age 48.5; range 17-81 years] and 105 female [58.0\%; mean age 45.8; range 14-68 years]) underwent endoscopic endonasal transsphenoidal resection. All patients were treated at a single medical center and by the same surgeon (Dr Gang Zhao, Director of the Department of Neurosurgery, The First Hospital of Jilin University). Of the 181 subjects included in the study, $66(36.5 \%)$ had a nonfunctioning pituitary adenoma, 49 (27.1\%) had PRL-pituitary adenomas, 28 (15.5\%) had GH-pituitary adenomas, 16 (8.8\%) had ACTH-pituitary adenomas, 9 (5.0\%) had FSH-pituitary adenomas, and 5 (2.8\%) had TSH-pituitary adenomas; moreover, 8 (4.4\%) mixed pituitary adenomas were included. By tumor size, there were only $30(16.6 \%)$ microadenomas and the remaining $151(83.4 \%)$ were macroadenomas. Patient characteristics are shown in Table 2.

Association of clinical characteristics with risk of postoperative hypokalemia

To explore statistical association between demographic and clinical characteristics and postoperative hypokalemia, a multivariate logistic regression model was used. Only the ACTH-pituitary adenoma was associated with a statistically significant increased risk of postoperative hypokalemia compared to non- 
156 ACTH-pituitary adenomas $(\mathrm{OR}=4.92 ; 95 \% \mathrm{CI}: 1.18-20.48, P=0.029$; Table 3$)$. Univariate analyses of

157 characteristics associated with the risk of postoperative hypokalemia are presented in Table 2.

158 Rural/urban geography significantly contributed to the definition of the influence factors. Rural patients

159 were more likely to have postoperative hypokalemia (OR=3.89; 95\%CI: $1.07-14.14, P=0.040)$. The OR

160 for association of postoperative hypokalemia with length of hospital stay showed postoperative

161 hypokalemia occurred more frequently in the group with stay $\geq 12$ days $(\mathrm{OR}=3.24 ; 95 \% \mathrm{CI}: 1.12-9.38$,

$162 P=0.030$ ) than the other group (length of hospital stay $<12$ days). In comparison with non-hypertensive

patients, patients with hypertension had a higher OR of postoperative hypokalemia $(\mathrm{OR}=5.11 ; 95 \% \mathrm{CI}$ :

1.76-14.80, $P=0.003)$. ACTH-pituitary adenomas were associated with an increased OR of postoperative

hypokalemia compared with non-ACTH-pituitary adenomas ( $\mathrm{OR}=19.63 ; 95 \% \mathrm{CI}$ : 5.82-65.84, $P<0.001)$,

whereas no statistically significant differences in incidence rates between postoperative hypokalemia and

the remaining factors (Table 2) were evident.

Variations of serum potassium at different time points in postoperative hypokalemia

Of the 181 subjects with pituitary adenoma, 16 patients had postoperative hypokalemia. The group with

patients who developed postoperative hypokalemia comprised 8 ACTH, 2 PRL, 2 non-functioning, 2 GH,

$1 \mathrm{TSH}$, and 1 mixed pituitary adenoma. To evaluate the impact of ACTH on postoperative hypokalemia group (ACTH group) and the non-ACTH-pituitary adenoma group (control group) and compared serum potassium levels between the 2 groups. From the third postoperative day onwards, the overall mean serum 
day. On the day of surgery, mean serum potassium in the ACTH and control groups was 2.92 and

$3.32 \mathrm{mmol} / \mathrm{L}$, respectively $(P=0.035)$; on the first postoperative day, the mean serum potassium

concentration was significantly lower in the ACTH group compared to control group (ACTH

$3.14 \mathrm{mmol} / \mathrm{L}$; control $3.71 \mathrm{mmol} / \mathrm{L}, P=0.021$ ). On the second and third postoperative days, the mean

serum potassium was 3.46 and $3.86 \mathrm{mmol} / \mathrm{L}$ in the ACTH group, and 3.94 and $4.21 \mathrm{mmol} / \mathrm{L}$ in the control

group, without any statistically significant between-group differences $(P=0.058$ and $P=0.150$, respectively;

Table 4). Levels of serum potassium in the study groups at each time point are shown in Figure 1.

Summary statistics for average serum potassium and levels at the 4 time points they were measures at are

presented in Table 4. Repeated measures ANOVA was used to analyze the interaction between the

subgroup of postoperative hypokalemia and the measurement time points, the result showed that the

interaction between postoperative hypokalemia and time is not statistically significant $(P=0.321)$, and a

statistically significant correlation and that postoperative hypokalemia was predominant among patients

with ACTH-pituitary adenomas $(P=0.033)$.

\section{DISCUSSION}

The ACTH-secreting pituitary adenoma is related to a clinical disorder known as Cushing's disease (CD),

which causes adrenal hypercortisolemia and consequent osteoporosis, muscle atrophy, psychiatric

disorders, and, ultimately, death(Castinetti et al., 2012; Sulentic et al., 2000). ACTH-pituitary adenomas

are recognized as a more aggressive and invasive subtype of pituitary adenomas(Jesser et al., 2014; Lake

et al., 2013; Maragliano et al., 2015). Total-body potassium is predominantly present as an intracellular 
198 199

200

201

202

203

204

205

206

207

208

209

210

211

212

213

214

215

216

217

affects multiple organ systems, and contributes to a significant risk of morbidity and mortality(Crop et al., 2007; Jordan \& Caesar, 2015).

In all of the 181 subjects in this study, serum potassium levels were normal preoperatively. However, $16(8.8 \%)$ patients with pituitary adenomas developed postoperative hypokalemia although conventional potassium supplementation was instituted immediately after surgery. This electrolyte disturbance is neither drug nor management related, and appears during the intraoperative period. Serum potassium was lower in the ACTH group compared to the control group, indicating that ACTH may play an important role in postoperative hypokalemia. Besides, compared with non-ACTH pituitary adenomas, the levels of serum potassium in ACTH pituitary adenomas patients were lower in the day and the first day of postoperation, but this phenomenon disappeared in the second day and the third day of postoperation.

According to these results, ACTH-pituitary adenomas was significant association with the elevated incidence of hypokalemia and reducing the ability of patients with hypokalemia to recover normal revels of potassium.

It has been demonstrated that $\mathrm{CD}$ can cause hypokalemia because of the changing levels of hormones(Campusano et al., 1999; Fernandez-Rodriguez et al., 2008). Therefore, potassium supplementation is undertaken for patients with ACTH-pituitary adenoma. Preoperative surgical planning includes confirmation that serum potassium levels are normal. Moreover, conventional potassium supplementation has been carried out in the immediate postoperative period as a preventive measure. In this study, however, half of the patients with postoperative hypokalemia were those with ACTH-pituitary adenomas who were preoperatively drug-naïve of potassium supplementation. We hypothesized intraoperative low potassium content was the cause of postoperative hypokalemia. First, it is well known 
219 that glucocorticoid and mineralocorticoid release intraoperatively usually counters the fall in serum potassium(Chauhan et al., 2015; Fox et al., 2016; Frindt \& Palmer, 2012; Lang \& Vallon, 2012; Ohtake adenomas are predisposed to high glucocorticoid levels, which can cause hypokalemia(Bondugulapati et al., 2016; Carrasco \& Villanueva, 2014; Cassarino et al., 2016). Second, all subjects in this study underwent endoscopic endonasal transsphenoidal tumorectomy, wherein cells of the pituitary gland were destroyed thus releasing hormones intraoperatively; simultaneously, tumor tissues were extruded and further hormone secretion. In the group with ACTH-pituitary adenomas, ACTH levels increased greatly in a short time. To further confirm the effect of surgical resection on postoperative hypokalemia, we should intraoperatively monitor changes in ACTH and serum potassium levels. This study elucidates the potential etiopathology of postoperative hypokalemia in patients with pituitary adenomas.

There are certain limitations of our study that should be acknowledged. First, only 16 patients with

ACTH-pituitary adenomas were included in our study. A moderate sample size prevented assessment of the effects of the clinical characteristics of ACTH-pituitary adenomas on postoperative hypokalemia.

Second, we only included subjects of ethnic Han lineage in northeastern China, and this may further introduce a heterogeneity with regard to the rest of the Han population in other regions. Further studies including a larger sample of patients with ACTH-pituitary adenomas are needed to validate our findings.

Finally, inherent to the study's retrospective design, selection and information biases could not be excluded. In addition, the data from medical records and the retrospective nature of the case-control methodology represent limitations of this study because they preclude determining the causal direction of the variables analyzed with any certainty. Our elucidation of the causative pathology of postoperative 
240 hypokalemia in ACTH-pituitary adenomas were based on hypotheses inferred from our study results and 241 should be further verified.

242 CONCLUSIONS

243 In summary, ACTH-pituitary adenomas may cause postoperative hypokalemia in patients despite 244 conventional potassium supplementation in the immediate postoperative period. However, more 245 experimental research and clinical studies are needed to determine the influence of the ACTH-pituitary 246 adenoma on postoperative hypokalemia and its etiopathologic mechanism. 
248

249

250

251

252

253

254

255

256

257

258

259

260

261

262

263

264

265

266

267

268

\section{REFERWNCES}

Bondugulapati LN, Campbell C, Chowdhury SR, Goetz P, Davies JS, Rees DA, and Hayhurst C. 2016. Use of day 1 early morning cortisol to predict the need for glucocorticoid replacement after pituitary surgery. Br J Neurosurg 30:76-79 DOI 10.3109/02688697.2015.1071325

Campusano C, Arteaga E, Fardella C, Cardenas I, and Martinez P. 1999. [Cushing syndrome by ectopic ACTH secretion: analysis of the physiopathologic mechanism of hypokalemia. Report of two cases]. Rev Med Chil 127:332-336

Carrasco CA, and Villanueva GP. 2014. [Selective use of glucocorticoids during the perioperative period of transsphenoidal surgery for pituitary tumors]. Rev Med Chil 142:1113-1119 DOI $10.4067 / \mathrm{s} 0034-98872014000900004$

Cassarino MF, Sesta A, Pagliardini L, Losa M, Lasio G, Cavagnini F, and Pecori Giraldi F. 2016. Proopiomelanocortin, glucocorticoid, and CRH receptor expression in human ACTH-secreting pituitary adenomas. Endocrine DOI 10.1007/s12020-016-0990-x

Castinetti F, Morange I, Conte-Devolx B, and Brue T. 2012. Cushing's disease. Orphanet J Rare Dis 7:41 DOI 10.1186/1750-1172-7-41

Chauhan V, Dev S, Pham M, Lin S, and Heidenreich P. 2015. Facility variation and predictors of serum potassium monitoring after initiation of a mineralocorticoid receptor antagonist in patients with heart failure. Am Heart J 170:543-549 DOI 10.1016/j.ahj.2015.06.006

Constantino ER, Leal R, Ferreira CC, Acioly MA, and Landeiro JA. 2016. Surgical outcomes of the endoscopic endonasal transsphenoidal approach for large and giant pituitary adenomas: institutional experience with special attention to approach-related complications. Arq 
Neuropsiquiatr 74:388-395 DOI 10.1590/0004-282x20160042

270

271

272

273

274

275

276

277

278

279

280

281

282

283

284

285

286

287

288

289

Crop MJ, Hoorn EJ, Lindemans J, and Zietse R. 2007. Hypokalaemia and subsequent hyperkalaemia in hospitalized patients. Nephrol Dial Transplant 22:3471-3477 DOI 10.1093/ndt/gfm471

Ezzat S, Asa SL, Couldwell WT, Barr CE, Dodge WE, Vance ML, and McCutcheon IE. 2004. The prevalence of pituitary adenomas: a systematic review. Cancer 101:613-619 DOI 10.1002/cncr.20412

Fernandez-Rodriguez E, Villar-Taibo R, Pinal-Osorio I, Cabezas-Agricola JM, Anido-Herranz U, Prieto A, Casanueva FF, and Araujo-Vilar D. 2008. Severe hypertension and hypokalemia as first clinical manifestations in ectopic Cushing's syndrome. Arq Bras Endocrinol Metabol 52:1066-1070

Fox LC, Davies DR, Scholl JL, Watt MJ, and Forster GL. 2016. Differential effects of glucocorticoid and mineralocorticoid antagonism on anxiety behavior in mild traumatic brain injury. Behav Brain Res 312:362-365 DOI 10.1016/j.bbr.2016.06.048

Frindt G, and Palmer LG. 2012. Regulation of epithelial $\mathrm{Na}+$ channels by adrenal steroids: mineralocorticoid and glucocorticoid effects. Am J Physiol Renal Physiol 302:F20-26 DOI 10.1152/ajprenal.00480.2011

Glover P. 1999. Hypokalaemia. Crit Care Resusc 1:239-251

Gold EB. 1981. Epidemiology of pituitary adenomas. Epidemiol Rev 3:163-183

Halperin ML, and Kamel KS. 1998. Potassium. Lancet 352:135-140 DOI 10.1016/s01406736(98)85044-7

Jesser J, Schlamp K, and Bendszus M. 2014. [Pituitary gland tumors]. Radiologe 54:981-988 DOI 
291

292

293

294

295

296

297

298

299

300

301

302

303

304

305

306

307

308

309

310

Jordan M, and Caesar J. 2015. Hypokalaemia: Improving the investigation, management and therapeutic monitoring of hypokalaemic medical inpatients at a district general hospital. $B M J$ Qual Improv Rep 4 DOI 10.1136/bmjquality.u209049.w3670

Lake MG, Krook LS, and Cruz SV. 2013. Pituitary adenomas: an overview. Am Fam Physician $88: 319-327$

Lang F, and Vallon V. 2012. Serum- and glucocorticoid-inducible kinase 1 in the regulation of renal and extrarenal potassium transport. Clin Exp Nephrol 16:73-80 DOI 10.1007/s10157-011-0488-z

Lodin K, and Palmer M. 2015. [Investigation of hypokalemia]. Lakartidningen 112

Maragliano R, Vanoli A, Albarello L, Milione M, Basturk O, Klimstra DS, Wachtel A, Uccella S, Vicari E, Milesi M et al. . 2015. ACTH-secreting pancreatic neoplasms associated with Cushing syndrome: clinicopathologic study of 11 cases and review of the literature. Am J Surg Pathol 39:374-382 DOI 10.1097/pas.0000000000000340

Melmed S. 2011. Pathogenesis of pituitary tumors. Nat Rev Endocrinol 7:257-266 DOI 10.1038/nrendo.2011.40

Melmed S. 2015. Pituitary tumors. Endocrinol Metab Clin North Am 44:1-9 DOI 10.1016/j.ecl.2014.11.004

Mete O, and Asa SL. 2012. Clinicopathological correlations in pituitary adenomas. Brain Pathol 22:443453 DOI 10.1111/j.1750-3639.2012.00599.x

Ohtake M, Hattori T, Murase T, Takahashi K, Takatsu M, Ohtake M, Miyachi M, Watanabe S, Cheng XW, Murohara T et al. . 2014. Glucocorticoids activate cardiac mineralocorticoid 
receptors in adrenalectomized Dahl salt-sensitive rats. Nagoya J Med Sci 76:59-72

312

313

314

315

316

317

318

319

320

321

322

323

324

325

326

327

328

329

330

331

Salyer SA, Parks J, Barati MT, Lederer ED, Clark BJ, Klein JD, and Khundmiri SJ. 2013. Aldosterone regulates $\mathrm{Na}(+), \mathrm{K}(+)$ ATPase activity in human renal proximal tubule cells through mineralocorticoid receptor. Biochim Biophys Acta 1833:2143-2152 DOI 10.1016/j.bbamcr.2013.05.009

Scangas GA, and Laws ER, Jr. 2014. Pituitary incidentalomas. Pituitary 17:486-491 DOI 10.1007/s11102-013-0517-x

Sulentic P, Morris DG, and Grossman A. 2000. Cushing's Disease. In: De Groot LJ, Chrousos G, Dungan K, Feingold KR, Grossman A, Hershman JM, Koch C, Korbonits M, McLachlan R, New M et al. , eds. Endotext. South Dartmouth (MA): MDText.com, Inc.

Terker AS, and Ellison DH. 2015. Renal mineralocorticoid receptor and electrolyte homeostasis. Am $J$ Physiol Regul Integr Comp Physiol 309:R1068-1070 DOI 10.1152/ajpregu.00135.2015

Wang F, Zhou T, Wei S, Meng X, Zhang J, Hou Y, and Sun G. 2015. Endoscopic endonasal transsphenoidal surgery of 1,166 pituitary adenomas. Surg Endosc 29:1270-1280 DOI $10.1007 / \mathrm{s} 00464-014-3815-0$

Weir MR, and Espaillat R. 2015. Clinical perspectives on the rationale for potassium supplementation. Postgrad Med 127:539-548 DOI 10.1080/00325481.2015.1045814

Wojtaszek E, and Matuszkiewicz-Rowinska J. 2013. [Hypokalemia]. Wiad Lek 66:290-293

Zhan R, Ma Z, Wang D, and Li X. 2015. Pure Endoscopic Endonasal Transsphenoidal Approach for Nonfunctioning Pituitary Adenomas in the Elderly: Surgical Outcomes and Complications in 158 Patients. World Neurosurg 84:1572-1578 DOI 10.1016/j.wneu.2015.08.035 
Figure 1

Fig1. The Student's t test was used to analyze the levels of serum potassium after the operation of patients with postoperative hypokalemia in ACTH group and control group.

(A) The day of postoperation. (B) The first day of postoperation. (C) The second day of postoperation. (D) The thirs day of postoperation.

A

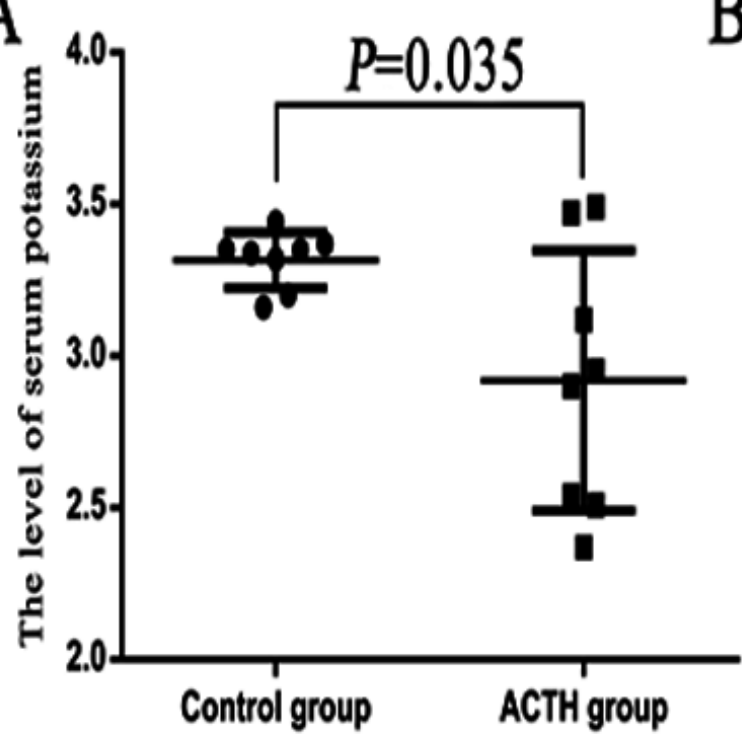

The day of postoperation

C

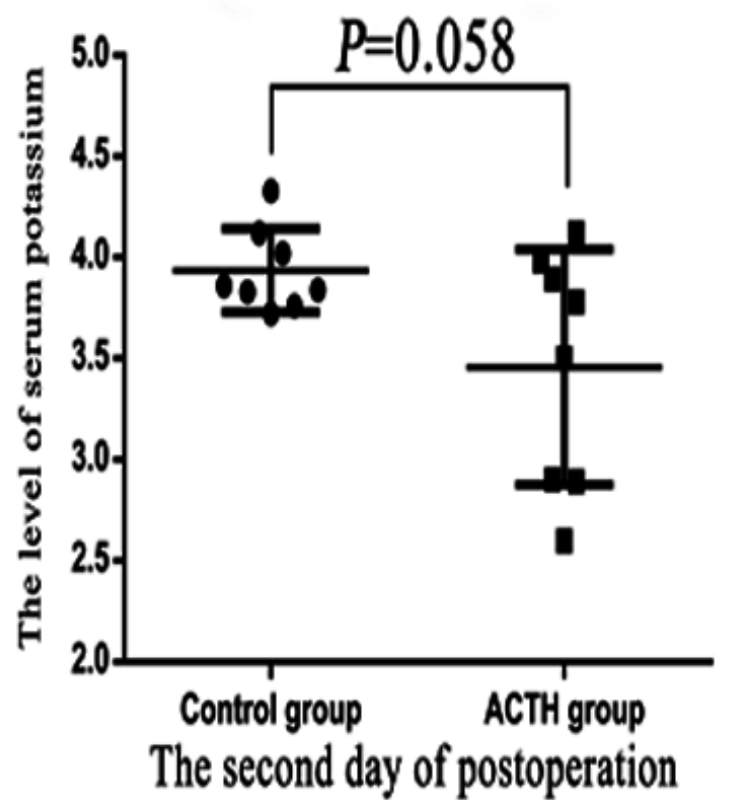

PeerJ reviewing PDF | (2017:02:16132:1:1:NEW 19 Apr 2017)
B

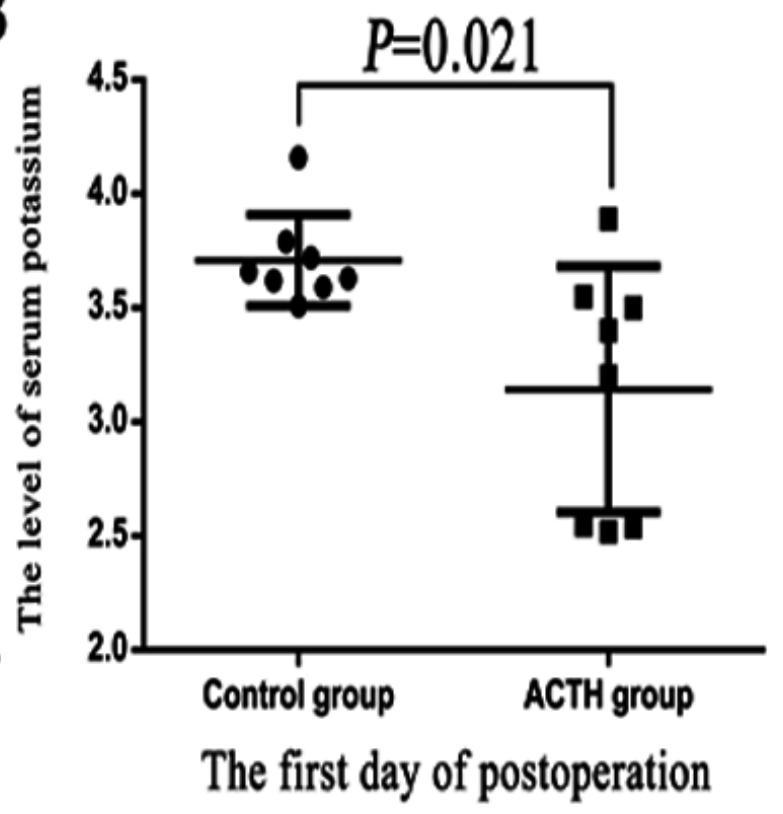

D

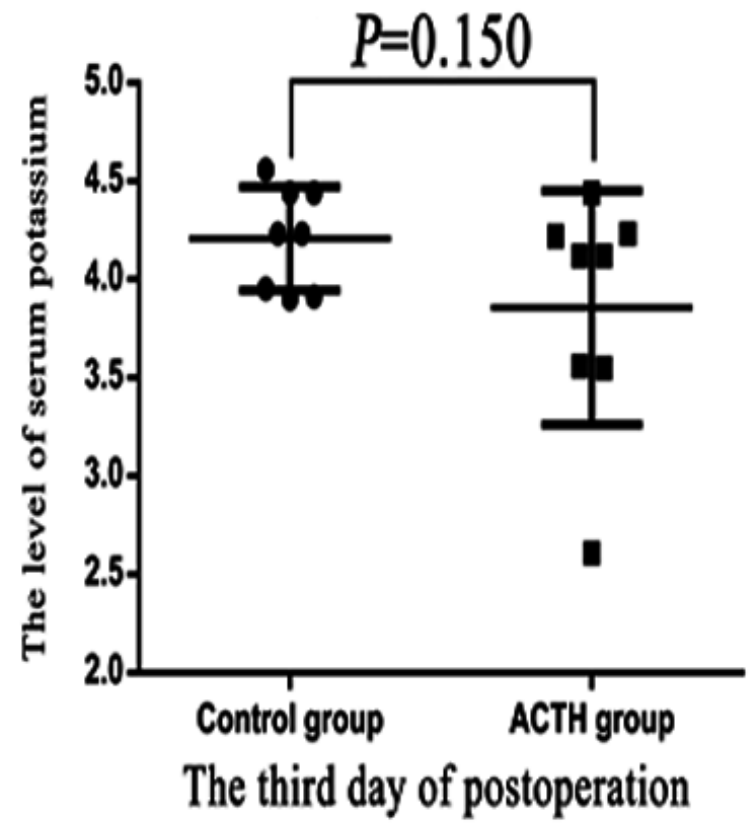




\section{Table $\mathbf{1}$ (on next page)}

Table 1 Diagnostic tests useful in the evaluation of the suspected pituitary adenomas $\mathrm{s}$ day 


\begin{tabular}{|c|c|c|c|}
\hline Tumor type & Diagnostic tests & reference range & Diagnostic tests notes \\
\hline PRL-pituitary adenoma & Serum prolactin & Elevated $(\geq 250 \mathrm{mcg} / \mathrm{L})$ & $\begin{array}{l}25-249 \mathrm{mcg} / \mathrm{L} \text { should prompt investigation of other } \\
\text { causes of hyperprolactinemia }\end{array}$ \\
\hline GH-pituitary adenoma & Insulinlike growth factor 1 & Elevated (76-328 ng/mL) & Normally elevated during pregnancy \\
\hline \multirow{4}{*}{ ACTH-pituitary adenoma } & $\begin{array}{l}\text { Oral glucose suppression } \\
\text { test }\end{array}$ & Elevated $(0-1 \mathrm{ng} / \mathrm{mL})$ & $\begin{array}{l}\text { Failure of growth hormone to decrease to }<1 \mathrm{ng} / \mathrm{mL} \\
\text { two hours after administering } 75 \mathrm{~g} \text { of oral glucose }\end{array}$ \\
\hline & 24-hour urine free cortisol & $\begin{array}{l}\text { Elevated }(10-84 \mathrm{mcg} \\
\text { total/24-hour period) }\end{array}$ & $\begin{array}{l}\text { Total high false-positive rate in women taking } \\
\text { estrogen diagnostic if four times greater than normal }\end{array}$ \\
\hline & Late-night salivary cortisol & $\begin{array}{l}\text { Elevated }(0.01-0.09 \\
\mathrm{mcg} / \mathrm{dL})\end{array}$ & Midnight sample \\
\hline & $\begin{array}{l}\text { 1-mg overnight } \\
\text { dexamethasone suppression }\end{array}$ & $\begin{array}{c}\text { Elevated (cortisol } \geq 1.8 \\
\mathrm{ng} / \mathrm{dL})\end{array}$ & $\begin{array}{l}\text { High false-positive rate in women taking estrogen and } \\
\text { further testing needed to rule out the source of excess } \\
\text { cortisol and to rule out "pseudo-Cushing syndrome" }\end{array}$ \\
\hline FSH-pituitary adenoma & FSH & FSH $(2-35 \mathrm{mIU} / \mathrm{mL})$ & $\begin{array}{l}\text { In postmenopausal women, elevated FSH levels are } \\
\text { normal, and value for menstruating women varies } \\
\text { based on phase of menstrual cycle }\end{array}$ \\
\hline \multirow[t]{2}{*}{ TSH-pituitary adenoma } & $\mathrm{TSH}$ & Elevated (0.5-4.8 mIU/L) & May be atypically normal in relation to free $\mathrm{T} 4$ \\
\hline & Free T4 & Low $(4.2-13$ ng/dL) & $\begin{array}{l}\text { Low T4 with normal or low TSH indicates secondary } \\
\text { hypothyroidism (possibly from pituitary dysfunction) }\end{array}$ \\
\hline Mixed- pituitary adenoma & $\begin{array}{l}\text { No specific corresponding } \\
\text { test }\end{array}$ & Combination of hormones & Varies based on dominant hormone \\
\hline Nonfunctioning- adenoma & None & None & None \\
\hline
\end{tabular}




\section{Table 2 (on next page)}

Table 2 Postoperative hypokalemia by demographic and clinical datas: Univariate analysis 


\begin{tabular}{|c|c|c|c|c|}
\hline Variables & Patients $(\%)$ & Hypokalemia (\%) & OR $(95 \% \mathrm{CI})$ & $P$ value \\
\hline \multicolumn{5}{|l|}{ Sex } \\
\hline Male & $76(42.0)$ & $7(9.2)$ & 1.00 & \multirow{2}{*}{0.881} \\
\hline Female & $105(58.0)$ & $9(8.6)$ & $0.92(0.33-2.60)$ & \\
\hline \multicolumn{5}{|l|}{ Age } \\
\hline$\leq 45$ & $80(44.2)$ & $6(7.5)$ & 1.00 & \multirow{2}{*}{0.573} \\
\hline$>45$ & $101(55.8)$ & $10(9.9)$ & $1.36(0.47-3.90)$ & \\
\hline \multicolumn{5}{|c|}{ Rural/urban geography } \\
\hline Urban & $81(44.8)$ & $3(3.7)$ & 1.00 & \multirow{2}{*}{0.040} \\
\hline Rural & $100(55.2)$ & $13(13.0)$ & $3.89(1.07-14.14)$ & \\
\hline \multicolumn{5}{|l|}{ Length of stay } \\
\hline$\leq 12$ days & $115(63.5)$ & $6(5.2)$ & 1.00 & \multirow{2}{*}{0.030} \\
\hline$>12$ days & $66(36.5)$ & $10(15.2)$ & $3.24(1.12-9.38)$ & \\
\hline \multicolumn{5}{|l|}{ Hypertension } \\
\hline No & $146(80.7)$ & $8(5.5)$ & 1.00 & \multirow{2}{*}{0.003} \\
\hline Yes & $35(19.3)$ & $8(22.9)$ & $5.11(1.76-14.80)$ & \\
\hline \multicolumn{5}{|l|}{ Diabetes } \\
\hline No & $162(89.5)$ & $12(7.4)$ & 1.00 & \multirow{2}{*}{0.059} \\
\hline Yes & $19(10.5)$ & $4(21.1)$ & $3.33(0.96-11.63)$ & \\
\hline \multicolumn{5}{|l|}{ Tumor size } \\
\hline$\leq 1.0 \mathrm{~cm}$ & $30(16.6)$ & $2(6.7)$ & 1.00 & \multirow{2}{*}{0.648} \\
\hline$>1.0 \mathrm{~cm}$ & $151(83.4)$ & $14(9.3)$ & $1.43(0.31-6.65)$ & \\
\hline \multicolumn{5}{|l|}{ Type } \\
\hline Nonfunctioning & $66(36.5)$ & $2(3.0)$ & 1.00 & \multirow{2}{*}{0.054} \\
\hline Functioning & $115(63.5)$ & $14(12.2)$ & $4.44(0.98-20.17)$ & \\
\hline \multicolumn{5}{|l|}{ Type } \\
\hline Non-PRL & $132(72.9)$ & $14(10.6)$ & 1.00 & \multirow{2}{*}{0.186} \\
\hline PRL & $49(27.1)$ & $2(4.1)$ & $0.36(0.08-1.64)$ & \\
\hline \multicolumn{5}{|l|}{ Type } \\
\hline Non-GH & $153(84.5)$ & $14(9.2)$ & 1.00 & \multirow{2}{*}{0.732} \\
\hline $\mathrm{GH}$ & $28(15.5)$ & $2(7.1)$ & $0.76(0.16-3.56)$ & \\
\hline \multicolumn{5}{|l|}{ Type } \\
\hline Non-ACTH & $165(91.2)$ & $8(4.8)$ & 1.00 & \multirow{2}{*}{$<0.001$} \\
\hline $\mathrm{ACTH}$ & $16(8.8)$ & $8(50.0)$ & $19.63(5.82-65.84)$ & \\
\hline \multicolumn{5}{|l|}{ Type } \\
\hline Non-FSH & $172(95.0)$ & $16(9.3)$ & 1.00 & \multirow{2}{*}{0.722} \\
\hline FSH & $9(5.0)$ & 0 & - & \\
\hline \multicolumn{5}{|l|}{ Type } \\
\hline Non-TSH & $176(97.2)$ & $15(8.5)$ & 1.00 & \multirow{2}{*}{0.391} \\
\hline $\mathrm{TSH}$ & $5(2.8)$ & $1(6.3)$ & $2.68(0.28-25.57)$ & \\
\hline
\end{tabular}




\begin{tabular}{lcccc} 
Non-Mix & $173(95.6)$ & $15(8.7)$ & 1.00 & 0.711 \\
Mix & $8(4.4)$ & $1(12.5)$ & $1.51(0.17-13.06)$ & \\
\hline
\end{tabular}

1 


\section{Table 3(on next page)}

Table 3 Postoperative hypokalemia by demographic and clinical datas: Multivariate analysis 


\begin{tabular}{lccc}
\hline \multicolumn{1}{c}{ Variables } & $\beta$ & OR $(95 \% \mathrm{CI})$ & $P$ \\
\hline Geography (Rural vs. Urban) & 1.01 & $2.74(0.69-10.88)$ & 0.151 \\
Length of stay (>12 days vs. $\leq 12$ days) & 0.96 & $2.62(0.81-8.51)$ & 0.109 \\
Hypertension (Yes vs. No) & 1.21 & $3.35(0.93-12.09)$ & 0.065 \\
ACTH-pituitary adenoma (Yes vs. No) & 1.59 & $4.92(1.18-20.48)$ & 0.029 \\
\hline
\end{tabular}

1 


\section{Table 4 (on next page)}

Table 4 Impacts of different groups on postoperative hypokalemia

* $F$ statistic and $P$ value of main effect; ${ }^{*} F$ statistic and $P$ value of crossover effect, and the mean of crossover effect is the interaction between postoperative hypokalemia and time. T1: day of surgery; T2: postoperative day 1; T3: postoperative day 2; T4: postoperative day 3 


\begin{tabular}{ccccccccc}
\hline \multirow{2}{*}{ Group } & & \multicolumn{9}{c}{ Measured at different time } & \multirow{2}{*}{ Sum } & $F$ & $P$ \\
\cline { 2 - 6 } & & $\mathrm{T} 1$ & $\mathrm{~T} 2$ & $\mathrm{~T} 3$ & $\mathrm{~T} 4$ & & & \\
\hline ACTH & $\overline{\mathrm{X}}$ & 2.92 & 3.14 & 3.46 & 3.86 & 3.34 & \multirow{2}{*}{0.552} & 0.010 \\
group & $s$ & 0.43 & 0.54 & 0.58 & 0.60 & 0.63 & & \\
Control & $\overline{\mathrm{X}}$ & 3.32 & 3.71 & 3.94 & 4.21 & 3.79 & 28.356 & $<0.001$ \\
group & $S$ & 0.09 & 0.20 & 0.21 & 0.26 & 0.38 & & \\
& $\overline{\mathrm{X}}$ & 3.12 & 3.43 & 3.70 & 4.03 & 3.57 & $5.625^{*}$ & \multirow{2}{*}{$0.033^{*}$} \\
Total & $S$ & 0.36 & 0.49 & 0.49 & 0.48 & 0.56 & & \\
& & 2.567 & 2.792 & 2.186 & 1.522 & & $(F=1.166, P=0.321)^{\#}$ \\
$P$ & & 0.035 & 0.021 & 0.058 & 0.150 & & & \\
\hline
\end{tabular}

1 